\title{
Convergent evolution of complex cognition: Insights from the field of avian cognition into the study of self-awareness
}

\author{
Luigi Baciadonna $^{1,2} \cdot$ Francesca M. Cornero ${ }^{2} \cdot$ Nathan J. Emery $^{1} \cdot$ Nicola S. Clayton $^{2}$ \\ Published online: 13 July 2020 \\ (C) The Psychonomic Society, Inc. 2020
}

\begin{abstract}
Pioneering research on avian behaviour and cognitive neuroscience have highlighted that avian species, mainly corvids and parrots, have a cognitive tool kit comparable with apes and other large-brained mammals, despite conspicuous differences in their neuroarchitecture. This cognitive tool kit is driven by convergent evolution, and consists of complex processes such as casual reasoning, behavioural flexibility, imagination, and prospection. Here, we review experimental studies in corvids and parrots that tested complex cognitive processes within this tool kit. We then provide experimental examples for the potential involvement of metacognitive skills in the expression of the cognitive tool kit. We further expand the discussion of cognitive and metacognitive abilities in avian species, suggesting that an integrated assessment of these processes, together with revised and multiple tasks of mirror self-recognition, might shed light on one of the most highly debated topics in the literature - self-awareness in animals. Comparing the use of multiple assessments of self-awareness within species and across taxa will provide a more informative, richer picture of the level of consciousness in different organisms.
\end{abstract}

Keywords Birds $\cdot$ Awareness $\cdot$ Comparative psychology $\cdot$ Consciousness $\cdot$ Mirror self-recognition $\cdot$ Self

Despite some avian species, primarily corvids and parrots, having been portrayed as astute beings in the folklore of many civilizations (with examples ranging from the observations of ancient Greeks and Norse and Native American mythology, to many of Aesop's fables and other popular tales), the study of intelligence has focused, traditionally, on our closest relative species, such as monkeys and apes and on a few other largebrained social mammals, such as elephants and cetaceans. Avian cognition was primarily investigated by using an anthropocentric approach in which a few avian species - mainly pigeons, chickens, and quails - had been extensively used to investigate the building blocks of cognition, such as associative learning and perception, that are shared in humans and nonhuman animals (Emery, 2016; Seed, Emery, \& Clayton, 2009; Wynne \& Udell, 2013). This is attributable to the

Luigi Baciadonna and Francesca M. Cornero are joint first authors

Luigi Baciadonna

luigi.baciadonna@qmul.ac.uk

1 Biological and Experimental Psychology, School of Biological and Chemical Sciences, Queen Mary University of London, London, UK

2 Department of Psychology, University of Cambridge, Downing Street, Cambridge CB2 3EB, UK widespread prior assumption that avian species were only capable of instinctual behaviours, did not have complex cognition, and that their brains were primitive. This understanding was influenced by Edinger's (1899) erroneous proposal that the avian brain is mainly composed of parts evolved from the striatum, a structure involved in instinctive behaviours, rather than the cortex.

However, in the mid-1900s early work by Thorpe on the mechanism of chaffinches' song acquisition highlighted a complex interplay between instinct and learning. By experimentally isolating the birds and providing a live tutor or a prerecorded song, Thorpe showed that the chaffinch first learns what to sing and then how to sing it. This observation initiated the neurophysiological investigation of the mechanisms involved in song development. Thorpe (1964) pointed out how the poor understanding of the evolution of the avian brain has affected our view of birds as capable of learning and cognition:

The poor development in birds of any brain structures clearly corresponding to the cerebral cortex of mammals led to the assumption among neurologists not only that birds are primarily creatures of instinct, but also that they are very little endowed with the ability to learn. There is no doubt that this preconceived notion, based 
on a misconceived view of brain mechanisms, hindered the development of experimental studies on bird learning. (p. 336)

The implications of these early studies on song acquisition in Oscines species were not lost on Pepperberg, who noticed that existing data on bird song was beginning to suggest parallels between song acquisition in songbirds and the vocal learning ability of parrots, including the importance of imitation (e.g., Lorenz, 1952; Marler, 1970; Mowrer, 1950), the existence of a practice or "babbling" period (e.g., Marler, 1970; Mowrer, 1950; Thorpe, 1964), and the presence of specific "song" brain areas that might also be involved in the production of other types of vocalizations (e.g., Nottebohm, $1970,1980)$. She decided to use grey parrots as a model to develop a referential, interspecies communication system, as had previously been done with apes (e.g., Gardner \& Gardner, 1969; Pepperberg, 1999, 2002b; Premack, 1971; Rumbaugh et al., 1973), but more importantly to use this communication system as a tool to study complex cognitive abilities, especially those that would otherwise have been difficult or impossible to access without it, as well as advanced, learned abilities that she termed "exceptional learning" (Pepperberg, 1999, 2002b). To establish such a functional, referential communication system, Pepperberg reasoned that earlier failures were likely due to ineffective training methods (Pepperberg, 2002a) and set out to find more ecologically valid alternatives.

Early work by Todt (1975) had shown the effectiveness of a social training method he called the model/rival (M/R) technique to teach Grey parrots to produce vocal labels: This technique required a principal human trainer, who asked questions to another human model, who then responded to the trainer as if he were the parrot subject, all while the actual parrot being trained watched. The responding human thus acts both as a model for desirable behaviour and responses, as well as a rival to the parrot for the attention of the principal trainer (Todt, 1975). Pepperberg modified the $M / R$ to become additionally interactive and more contextually rich by including three-way interactions between both human trainers and the parrot subject - such that neither human is the principal trainerand to hold referential value by making use of the objects that were being used for training as the reward itself, rather than an external, irrelevant food reward, in practice assigning a referential and contextual use to the label being trained (Pepperberg, 1999). Pepperberg also validated this training method and showed, by examining piece-wise modifications of this training, that removing or lessening the referential, contextual, and socially interactive aspects of the procedure (as well as any subset of these) resulted in lessened or interrupted learning (Pepperberg, 1994b, 2000; Pepperberg, Gardiner, \& Luttrell, 1999; Pepperberg \& Wilkes, 2004).

With the use of this adapted M/R technique, Pepperberg succeeded in establishing a referential, verbal interspecies communication system with parrots (initially one and later others), the most notable of which, Alex, learned more than 100 different labels, including those for seven colours, six shapes, eight numbers, several foods, and categories, plus phrases used to request actions from his trainers, such as "Wanna go X, I want Y" (where X and Y are placeholders for locations and objects in the lab, respectively; Pepperberg, 1987a, 1992a, 1994a). With this social, interactive training model, she was able to investigate several complex cognitive abilities, including Alex's understanding of the concepts of "same" and "different": When shown two objects, he was able to identify the specific category they either shared or differed in, depending on the question and the specific attributes of the set-for instance, responding "shape" when asked about the similarity of two triangles of different materials and colours (Pepperberg, 1987a). If the question posed had no correct answer, he used the label "none" to indicate that circumstance (Pepperberg, 1988), a concept he later transferred to denoting a lack of a size difference in two objects (Pepperberg \& Brezinsky, 1991), and later to the absence of a numerical set (Pepperberg \& Gordon, 2005). Alex's understanding of a concept of absence even allowed investigation into his use of "none" as a "zero-like" concept, among other numerical abilities, including answering "how many?" up to "eight," and adding up to three small sets of up to eight objects or Arabic numerals, among others (Pepperberg, 1987b, 2006a, 2006b; Pepperberg \& Carey, 2012).

The study of avian cognition has been greatly amplified and diversified ever since, with a vast number of experiments investigating the advanced cognitive abilities of corvid species (for a nonexhaustive review, see Lambert, Jacobs, Osvath, \& Von Bayern, 2018). In the last decade, there has been a renovated interest in parrot cognition as well (Auersperg \& Von Bayern, 2019; Lambert et al., 2018). Such advances came together with developments in the neurobiological study of avian brains, which led credence to the idea that avian brain structures were indeed capable of supporting complex cognitive abilities. Yet even before such neurobiological data became available, Pepperberg used a very appropriate analogy to grasp the then-missing understanding of the relationship between avian and mammalian brains:

The metaphor I like to use involves looking at avian and mammalian brains as early Macintosh versus IBM-style computers: These different information-processing machines use the same wires, and when you enter the same data into their programs you get the same results - but the wires are organized differently and you must use programs designed for their differently configured systems. (Pepperberg, 1999, pp. 9)

An analogy that is still useful decades later. 
We will now summarize recent developments in the scientific understanding of bird brains and discuss experimental evidence for the existence of complex cognition in members of the corvid and/or parrot families. The cognitive abilities that we will examine are part of a cognitive tool kit that evolved convergently in different bird and mammal species. We argue that the abilities demonstrated within such a tool kit involve the ability to assess and monitor internal states, also defined as metacognition. We will develop this argument further and propose that research into metacognition and revised tests of self-recognition can be used to provide evidence of selfawareness in avian species.

\section{Neurobiological evidence: The avian brain}

The complex cognitive abilities demonstrated by corvid and parrot species (some of which will be discussed in more detail in the next section) were thought to be unlikely because of Edinger's assumption that the brain of avian species was mainly composed of regions evolved from the striatum, and thus unlikely to be capable of complex cognition (Edinger, 1899). The availability of more advanced technology and research efforts by the Avian Brain Nomenclature Consortium have challenged this initial erroneous assumption (Jarvis et al., 2005; Jarvis et al., 2013; Reiner et al., 2004). Part of the avian telencephalon derives from the pallium of a stem amniote ancestor shared among all mammals, reptiles, and birds. In mammals, during the course of evolution, the dorsal region of the pallium expanded to form the neocortex. The ventral pallium remained small, with the medial pallium forming the hippocampus, the lateral pallium forming the olfactory cortex, and the ventral pallium forming the amygdala. In reptiles and birds, a ventralization of the pallium occurred instead. In reptiles, the medial, dorsal, and lateral pallium regions remained small, while the ventral pallium expanded. Similarly, in birds, the ventral pallium expanded further, and the dorsal pallium evolved into the Wulst. In birds, the lateral and ventral regions of the pallium seem to play a key role in cognition (Clayton \& Emery, 2015; Emery, 2016). Although the structure and organization of the avian brain (nuclear) is different from the mammalian (layered) brain, they do process similar information in equivalent ways (L. Medina \& Reiner, 2000; Jarvis et al., 2013). In fact, a strong similarity in different sensory systems, like visual and auditory systems, and even in motor systems, exists between mammals and birds, suggesting an underpinning convergent evolution (L. Medina \& Reiner, 2000; Shimizu, Patton, \& Husband, 2010; Shimizu \& Watanabe, 2012). Furthermore, complex cognition in birds is thought to be supported by a brain region called nidopallium caudolaterale (NCL) that is thought to be functionally equivalent to the prefrontal cortex (PFC) of mammals (Güntürkün, 2005; Güntürkün \& Bugnyar, 2016). For example, evidence based on connectivity studies have highlighted that NCL has a crucial role in receiving and processing information and affects behaviour through its connection with the striatum in a similar fashion to the mammalian PFC (Güntürkün, 2005; Güntürkün \& Bugnyar, 2016). Lesion studies and evidence of its being densely populated by dopamine receptors (D1 and D2) support the assumption that the NCL plays a role in the executive function tasks (Clayton \& Emery, 2015; Güntürkün, 2005; Güntürkün \& Bugnyar, 2016). In addition, the involvement of the basal ganglia (striatum) in song learning (social modulation) does not support the statement that its role is only confined to behaviours guided by instinct (Hessler \& Doupe, 1999; Reiner et al., 2004).

Additionally, parrots, as well as some passerine birds including corvids, have significantly larger brains and cortex than most nonpasserine birds relative to their body sizes, and in some cases larger than or comparable to that of primates of the same body mass (Iwaniuk, Dean, \& Nelson, 2005). Birds in general were found to have two brainstem pontine nuclei that connect the telencephalon and the cerebellum, something mammals also have and that is thought to be associated with the evolution of complex cognitive abilities (Gutiérrez-Ibáñez, Iwaniuk, \& Wylie, 2018). Birds also have an additional nucleus in this system, which is enlarged in parrots and highly correlated with telencephalon size; this pathway may be analogous to the pathways controlling fine motor skills and complex cognitive processes in mammals (Gutiérrez-Ibáñez et al., 2018). Most parrots, with the exception of the New Zealand keas, have also been found to have an additional "song system" in their brains, forming a shell around the primary song system common to parrots, songbirds, and hummingbirds (species considered to be vocal learners; Chakraborty et al., 2015). Considering the ubiquity of this additional "shell" system in the brains of parrots with advanced vocal mimicry abilities, as well as its absence, except in a rudimentary fashion, in the brain of the kea, a species not known to be very skilled at vocal reproduction, this system is thought to be responsible for the advanced abilities of most parrots to reproduce heterospecific vocalizations, and is also tentatively posited to be involved in advanced cognitive capacities (Chakraborty et al., 2015). The brains of songbirds and parrots have an extremely high density of neurons, with more neurons than primate brains of comparable mass (Olkowicz et al., 2016). In the corvids and parrots studied, neurons are especially densely packed in their forebrains (specifically in the pallial telencephalon); this finding suggests they may have more brain capacity per unit area than some mammals thought to be capable of more complex cognition (Olkowicz et al., 2016). Although there may be fundamental differences in the size and structure of avian and mammalian brains, they share analogous neuroanatomical components responsible for cognitive processes. The similarities are not limited to the neuroanatomical components underlying their cognitive 
processes, but rather birds and mammals might also represent their social and physical worlds in similar ways (Emery, 2004, 2006; Emery \& Clayton, 2004a; Seed et al., 2009; van Horik \& Emery, 2011).

\section{Complex cognition}

In light of this evidence, it is now unsurprising that similar complex cognitive abilities have been reported in corvids and primates, and that convincing evidence has been described also in parrots, elephants, and dolphins, suggesting a cognitive tool kit that has evolved independently several times (Emery, 2004; Emery \& Clayton, 2004a; Lambert et al., 2018; Marino, 2002; Marino et al., 2007; Plotnik \& Clayton, 2015; Seed et al., 2009; Tomasello \& Call, 1997; van Horik \& Emery, 2011; van Horik, Clayton, \& Emery, 2012). Emery and Clayton (2004b) suggested that, at least in corvids and apes, and more likely some other birds (e.g., parrots) and mammals (e.g., cetaceans), this cognitive tool kit consists of causal reasoning, behavioural flexibility, imagination, and prospection. Furthermore, they argued that it evolved in response to socioecological challenges (Emery \& Clayton, 2004b). These advanced cognitive skills were unlikely to be present 320 million years ago when birds and mammals shared a common ancestor, and therefore it is likely that this shared cognitive tool kit evolved independently in these two groups of species (Emery \& Clayton, 2004b; Kabadayi, Bobrowicz, \& Osvath, 2018; van Horik \& Emery, 2011; van Horik et al., 2012). By considering such cognitive abilities as adaptive specializations shaped by evolution, it is possible to obtain insights into the evolutionary challenges and problems each species needed to solve over its evolutionary history, and better understand cognitive mechanisms that arose to solve them (van Horik et al., 2012). However, because these different species evolved under similar socioecological challenges, it is possible to hypothesize that intelligence evolved through convergent evolution in this group in response to similar selective pressures and allow us to reconstruct the evolution of intelligence (Amodio, Boeckle, Schnell, et al., 2019b; Emery and Clayton, 2004a, b; Fox, Muthukrishna, \& Shultz, 2017). The conspicuous differences in evolutionary history and brain structure between species suggest that intelligence evolved independently several times and that different neural substrates can support similar cognitive capability (Güntürkün \& Bugnyar, 2016; Roth, 2015).

For example, corvids are well known for their abilities to use, manufacture, and innovate tools, and these can be considered advanced cognitive abilities in the physical domain, that make use of causal reasoning, flexibility, and imagination from this cognitive toolbox (Cheke, Bird, \& Clayton, 2011; Davidson, Miller, Loissel, Cheke, \& Clayton, 2017; Emery and Clayton, 2004a, b, 2009b; Jacobs, von Bayern, \&
Osvath, 2016; Kabadayi \& Osvath, 2017; Miller, Logan, Lister, \& Clayton, 2016; Rutz, Klump, et al., 2016a; Rutz, Sugasawa, van der Wal, Klump, \& Clair, 2016b; Sanz, Call, \& Boesch, 2013; Seed \& Byrne, 2010; Weir, Chappell, \& Kacelnik, 2002). Species that are not necessarily tool users or makers in the wild have been shown to do so in the laboratory (Auersperg, Szabo, Von Bayern, \& Kacelnik, 2012; Bird \& Emery, 2009a, 2009b; Cheke et al., 2011). In a series of ingenious tests, rooks were able to select the appropriate tool based on its physical appearance or to shape wire into a hook to retrieve food (Bird \& Emery, 2009a). Bird and Emery (2009), inspired by a Greek fable, also tested whether rooks grasped the floating properties of water to retrieve waxworms baited inside a transparent, water-filled cylinder (Bird \& Emery, 2009b). Rooks not only used stones to increase the level of the water but also selected the right number of stones and avoided unsolvable trials in which the cylinder was filled with sand. Similar experiments have been replicated in Eurasian jays and New Caledonian crows, showing to some extent the sophisticated causal properties of water displacement (Amodio, Boeckle, Jelbert, Ostoijc, \& Clayton 2019a; Amodio, Boeckle, Jelbert, Ostoijc, \& Clayton, 2019b; Cheke et al., 2011; Jelbert, Taylor, Cheke, Clayton, \& Gray, 2014; Jelbert, Taylor, \& Gray, 2015). Some parrot species have also displayed the ability to use and manufacture tools, primarily in the laboratory, but occasionally in the wild (Lefebvre, Nicolakakis, \& Boire, 2002; Shumaker, Walkup, \& Beck, 2011). Palm cockatoos have been observed to use sticks to drum against tree hollows in auditory displays in the wild (Wood, 1984), and there is evidence that some wild Goffin's cockatoo individuals may also already be using tools in a foraging context, or be at an evolutionary tipping point between flexible extractive foraging and true tool use (Osuna-Mascaró \& Auersperg, 2018). In captivity, there is anecdotal evidence of Grey parrots and cockatoos using objects in a tool-like fashion, such as for scratching themselves or, in at least one occasion, using the shell of a nut to collect water from a bowl for drinking (Boswall, 1977). Additionally, in experimental contexts, keas have shown the ability to select functional tools appropriately (Auersperg, Gajdon, \& Huber, 2010), and Goffin's cockatoos were found to manufacture, use, and modify stick and metal hook tools functionally (Auersperg, Borasinski, Laumer, \& Kacelnik, 2016; Auersperg et al., 2012; Laumer, Bugnyar, Reber, \& Auersperg, 2017). An interplay between behavioural predisposition, learning, and living conditions has been suggested to be the drive behind the evolution of tool use (Amodio, Jelbert, \& Clayton, 2018).

Mental time travel (MTT) is another complex cognitive skill found in some bird species. It is associated with flexibility and prospection from the cognitive toolbox, and defined as the ability to recall specific past experiences (episodic memory) and imagine future events in order to plan for them (future thinking; Clayton, Bussey, \& Dickinson, 2003a; Suddendorf 
\& Corballis, 1997; Suddendorf, T., Addis, D. R., \& Corballis, 2009; Tulving, 2005). The view that MTT is a uniquely human feature because it consists of the ability to recall subjective experiences (phenomenological aspects) and to project oneself into the past (reexperience) or future (preexperience) has been challenged by defining the behavioural elements of episodic cognition (Clayton, Bussey, et al., 2003a; Griffiths, Dickinson, \& Clayton, 1999). In 1998, Clayton and Dickinson proposed a definition of "episodic-like memory" that includes the behavioural elements (what, where, and when) of a specific event that nonhuman animals could recall. Capitalising on their natural propensity to store food, Clayton and Dickinson (1998) showed experimentally that scrub jays remember when, where, and what food they stored during a single previous experience (Clayton \& Dickinson, 1998, 1999). Californian scrub jays had the opportunity to cache perishable (waxworm) and long-lasting peanuts. The jays preferentially recovered the waxworms when the time delay interval was short, whereas peanuts were preferred to the waxworms (which could have decayed to be inedible) when the time interval was long (Clayton \& Dickinson, 1998). This experiment demonstrates that the jays' behaviour met the what, where, and when content criteria for episodic-like memory. To avoid the inedible food, the birds must have recalled what they have cached, where, and when. Because of the unique visual and spatial elements used in each cache site, the birds must have also remembered the what, where, and when linked with a single trial. This content, in scrub jays, forms an integrated structure that makes it possible to classify episodes that are not spatially and temporally related and to discriminate different episodes that share common aspects (e.g., when the animal recalls one aspect of a specific event, it will be able to retrieve the other components automatically (Clayton, Yu, \& Dikinson, 2001).

Jays also use the information retained in memory flexibly and across different contexts. For example, when scrub jays had the opportunity to cache perishable and long-lasting foods in different locations of a tray and subsequently experienced that the perishable food degraded faster than expected, they preferentially searched for the long-lasting food when given the opportunity to recache in the original tray (Clayton, $\mathrm{Yu}, \&$ Dickinson, 2003b). Scrub jays therefore are able to update their knowledge about the rate of degradation of food and to integrate this information with their bounded memory of a specific caching event to change their preference during the recovery time (Clayton, Bussey, et al., 2003a). To date, only scrub jays meet the behavioural properties of episodic-like memory, as defined in humans - namely, content, structure, and flexibility (Clayton, Bussey, et al., 2003a). Furthermore, scrub jays show the ability to plan spontaneously for the future in a way that is not dependent on motivational states (Cheke \& Clayton, 2012; Correia, Dickinson, \& Clayton, 2007; Emery \& Clayton, 2001; Raby, Alexis, Dickinson, \& Clayton, 2007).
In the initial experiment carried out by Raby et al. (2007), birds were moved in two different cages over 6 days, and only in one of the two rooms they received breakfast. After a period of training, the jays received food to eat and cache. The jays cached more food in the nonbreakfast cage, where they would have been hungry later, compared with the cage where breakfast was always provided. In a "breakfast-choice" experiment, they were always given breakfast, but each cage was associated with a specific type of food. In this case, instead of caching based on a conditioned response (association between a specific food and cage), they cached more based on maintaining variety in the food available later, suggesting their preference for having a choice. In a subsequent study (Correia et al., 2007), scrub jays were satiated on a type of food (reducing the motivation for one specific food relative to another option) before having the opportunity to cache that and other food options. Later, before the recaching event, the birds were fed with the same or a different food. The birds that were fed with the same food begun to cache preferentially the food they had not been satiated with, consistent with the expectation they would desire the different food at recovery. On the other hand, the group of birds that where fed with a different food just before the recovery trial recached the food they had been prefed with before the caching trial, despite the fact they had just been prefed with it before being allowed to cache. This supports the idea that those jays were able to cache food according to their future desires, rather than their current ones. In a follow-up experiment, Cheke and Clayton (2012) provided further evidence that the Eurasian jays are able to overcome their current needs to cache food that they will want to eat in the future, and furthermore that they can do so for two independent future motivational states.

Corvids also show remarkable, complex sociocognitive abilities (Emery, Seed, von Bayern, \& Clayton, 2007; Grodzinski \& Clayton, 2010), and some level of self-awareness would be highly advantageous, and perhaps even required, for successful life in complex social groups such as those of many corvids and parrots (Bond \& Diamond, 2019; Emery et al., 2007; Tebbich, Taborsky, \& Winkler, 1996). Early work by von Bayern and Emery on jackdaws shows a wide, accurate, and flexible range of social cues they can read and respond to appropriately, both from conspecifics (familiar individual) and heterospecifics (human distal pointing and gaze alternation and different levels of attention) during social interactions and cooperativecompetitive tasks to locate food sources (von Bayern \& Emery, 2009a, 2009b). Corvids often hide food to consume it in the future, and this posits a risk of it being pilfered, especially in species that forage in large social groups. Indeed, cacheprotection strategies employed by some corvid species have evolved to protect their food from a potential pilferer (Dally, Clayton, \& Emery, 2006a). The decision to protect the food is dependent on whether the conspecific is present or absent (Emery \& Clayton, 2001). When birds are caching in private 
(not seen by another conspecific) they tend not to protect their food, whereas they do so when being observed by another individual. In a more controlled setting, scrub jays and Eurasian jays adopt several appropriate strategies to protect their food, such as relocating the cached items in new locations, caching behind a barrier or further away from a direct competitor, in shady spots rather than well-lit ones, and also reducing indirect cues that would indicate the location of the caching zone, especially when observed by a potential pilferer (Dally, Emery, \& Clayton, 2004, 2005, 2006b; Emery \& Clayton, 2001; Legg \& Clayton, 2014; Legg, Ostojić, \& Clayton, 2016; Shaw \& Clayton, 2013; Tornick, Rushia, \& Gibson, 2016). Caching protection strategies are also dependent on social status (dominant vs. subordinate) and the relative risk posed by the observer (Clayton, Dally, \& Emery, 2007). The caching protection strategies used by some corvids underline a capacity of perspective taking and knowledge attribution from both the one that caches and the thief's perspective, such as a knowledge of what they themselves or others have or have not seen, or the use of apparently deceptive strategies such as the creation of false caches (Emery \& Clayton, 2009a). Interestingly, the adoption of caching strategies is dependent on having experience of stealing food and projecting this experience on others (Bugnyar, Reber, \& Buckner, 2016; Clayton et al., 2007; Dally, Emery, et al., 2006b; Emery and Clayton, 2004a, b, 2008; Grodzinski \& Clayton, 2010; Keefner, 2016). The hypothesis that corvids are able to take the prospective of others into account is validated also by food-sharing studies in which Eurasian jays take into account the desire of the female partner by offering, if given a choice and they had seen their partner being prefed, a type of food the partner had not previously consumed (Ostojić et al., 2014; Ostojić, Shaw, Cheke, \& Clayton, 2013). Ostojić and colleagues investigated whether male Eurasian jays could attribute changes in an internal desire state to their female within the context of food sharing during cooperative courtship behaviour. The desire for a particular food in the female was manipulated by satiation for that particular food, whereas the motivation to consume another type of food was left unaltered (Correia et al., 2007; Dickinson \& Balleine, 1995). In a series of experiments, the male Eurasian jays shared food by matching the females' current food preference (food she had not previously been satiated with). Males could only match the female's preferences when they had seen her being prefed, but did not match correctly when they had not, indicating they required information regarding the food females had previously consumed to do so, and the female was not behaviourally indicating what she wanted to them. A subsequent experiment in which males could not share food with the females, but rather only eat it themselves, also showed that the males' own desires had not been influenced by what food they had observed the female eat, and therefore their own preferences could not be the basis of their sharing behaviour (Ostojić et al., 2013). In another experiment, Ostojić and colleagues were able to demonstrate that Eurasian jays were partially able to disengage from their own current desire. In fact, when the desire of the pairs matched (being prefed on the same food), the male shared the food preferred by both; when the desired food did not match (being prefed on different foods), the sharing pattern was guided not entirely by his own desire but also by the desire of the partner (Ostojić, Cheke, Shaw, Legg, \& Clayton, 2016; Ostojić et al., 2014).

At least some, if not all, of the complex abilities discussed above implicate some level of metacognitive ability. In particular, here, we adopt a definition of metacognition that refers to the ability of an individual to access and monitor their own internal cognitive processes (e.g., what they have seen, know, and what they remember; Fernandez-Duque, Baird, \& Posner, 2000; Metcalfe, 2009; Terrace \& Son, 2009), regardless of the more advanced capacity to access metarepresentational states of the self (Carruthers, 2014). For example, in order to respond appropriately to novel and untrained socioecological challenges such as those involved in complex social cognition experiments, it is plausible to assume that individuals are able to access mental information to evaluate the risk and prospect of achieving their goal (Smith, 2009). Likewise, the ability to carry out separate actions in appropriate sequential fashion to solve a task (metatool use) requires the ability to realize what is known and what is unknown (Gruber et al., 2019; Taylor, Hunt, Holzhaider, \& Gray, 2007). More striking are abilities such as those involved in mental time travel, either to the past as episodic-like memory, or to the future as prospection, in which metarepresentational states may even be necessary: a jay's ability to form an integrated, "what-where-when" memory of a caching event, and then use this memory to make appropriate cache-recovery decisions, suggests some level of self-representation within this complete memory - a representation so full and complex surely must include some amount of the subject's own "self" in it. Likewise, the ability to cache appropriately with future needs in mind, separate from current motivational states, may be indicative of a representation of "self": It may require imagining one's own situation in the future, and acting accordingly in the present to benefit oneself when mentally projected into the future.

The existence of metacognitive abilities in psittacine species could also be inferred from their performance on cognitive tasks. For example, some of Alex's abilities suggest his use of higher level cognitive processes, presumably requiring some monitoring of processes at lower levels. For instance, his ability to correctly answer questions regarding the number of objects within a mixed set that fulfilled one or more categorical criteria, such as "How many keys?" for a tray with a certain number of keys mixed with a certain number of pieces of cork (Pepperberg, 1987b), or "How many purple wood?" for a tray holding, for instance, one orange piece of chalk and two orange pieces of wood, intermixed with four purple pieces of wood and five purple pieces of chalk (Pepperberg, 1994a), 
cannot be explained by using a simple perceptual mechanism such as subitizing; rather, it requires cognitive reflection on the appropriate conjunction of features requested, in addition to counting of the objects fulfilling such criteria and disregarding those that do not, to produce a correct answer (Pepperberg, 1992a, b, c). Additionally, Alex's use of the label "none" to answer to a lack of perceptual similarity or size difference between two objects (Pepperberg, 1988; Pepperberg \& Brezinsky, 1991), as well as the absence of a numerical set (Pepperberg \& Gordon, 2005), likewise required more complex processing of information and of the correct solution to a question, or lack thereof, rather than use of perceptual cues or simple associations alone. However, a handful of studies with Grey parrots suggest they may also be appropriate subjects for direct metacognitive investigation. These experiments (probabilistic reasoning, Clements, Gray, Gross, \& Pepperberg, 2018; inference by exclusion, Mikolasch, Kotrschal, \& Schloegl, 2011; Pepperberg, Gray, Mody, Cornero, \& Carey, 2019; Pepperberg, Koepke, Livingston, Girard, \& Hartsfield, 2013) were not designed to examine, and cannot conclusively show, metacognitive abilities, but because of the requirements of the tasks, their results were consistent with the possibility that the parrots were accessing, or at least using information from, their own states of certainty or uncertainty regarding the "correct" choices for each task in order to enable successful responses. Such evidence, suggestive of at least some awareness of the parrots' state of their own knowledge, highlights the need for dedicated metacognitive studies in psittacine species to complement the data from these experiments and allow for better comparisons with other species already examined.

Beyond this indirect evidence of metacognitive skills in corvids and parrots, more formal tests of metacognitive abilities have also been conducted in some avian species. Metacognition is often assessed in non-human animals using the opt-out and the information-seeking paradigms (Grodzinski, Watanabe, \& Clayton, 2012; Smith, 2009; Smith, Couchman, \& Beran, 2014). The underlying idea of these paradigms is to challenge an individual with an uncertain situation and quantify their escape responses or information-seeking behaviour. An uncertain response is interpreted as indirect evidence of the subject's awareness of their own state of knowledge (Call \& Carpenter, 2001). However, this claim requires further assessments, such as those testing the flexibility of the behaviour. Watanabe and colleagues (Grodzinski et al., 2012; Watanabe, Grodzinski, \& Clayton, 2014) tested the flexibility of the behaviour exhibited by Western scrub jays in a task that required them to allocate different observational times under different circumstances in order to locate food. In the forced-choice condition, it was essential to observe the hiding procedure to later retrieve the reward. After being given the possibility of experiencing the consequences of having information in each condition, the birds made more looks and spent more time looking through the peephole in the free-choice condition where, in other words, the information was necessary. The jays' flexible behaviour (based on current knowledge and reward evaluation) cannot be explained by simpler associative/conditioning learning, but rather should be interpreted as evidence of metacognitive abilities.

We propose that the complex cognitive and metacognitive abilities demonstrated in avian species (e.g., the ability to recall the past and imagine the future, perspective taking, and access to one's own states of knowledge) imply some degree of self-awareness must be present within them. One limitation in the study of self-awareness in nonverbal animals is that it has overrelied on the use of one test, mainly the mark test (Gallup, 1970). In the next section, we review the evidence for the mark test in avian species and propose the use of a wider conceptualization of self-awareness that can be captured using multiple assessments and evaluating individuals' performance on a continuous scale rather than on pass or fail criteria.

\section{Mirror use experiments in avian species}

Typically, mirror studies investigate the ability (or failure) of an animal to recognize itself in a mirror (mirror selfrecognition; MSR) using the mark test designed by Gallup (1970). Prior to the mark test, animals are generally given the opportunity to experience a mirror (mirror image stimulation; MIS). When exposed to a mirror, many animals first respond to their reflections with social displays. Over time, their behaviour towards the mirror becomes more self-directed. Following mirror exposure, subjects are restrained, and a real or sham mark is placed on a body region that can only be seen in front of the mirror. It is assumed that only subjects that touch or attempt to remove the mark from their body more than the sham mark and in the presence of the mirror more than when a mirror is not available are self-aware. To date, in the avian field, only a few species have been formally tested for MSR. Among those, only magpies and Indian crows have been reported to successfully pass this test, although the evidence provided is highly controversial (Anderson \& Gallup, 2015; Buniyaadi, Taufique, \& Kumar, 2020; Gallup \& Anderson, 2018; Prior, Schwarz, \& Güntürkün, 2008). Somatosensory feedback enhanced by the application of the mark and intrinsic motivational factors have been identified as the main crucial factors that might underline this patchy pattern of findings across avian species, as well as in other species (Anderson \& Gallup, 2015; Buniyaadi et al., 2020; De Veer \& Van Den Bos, 1999; Gallup \& Anderson, 2018; Heyes, 1994, 1995, 1996; Prior et al., 2008; Soler, PérezContreras, \& Peralta-Sánchez, 2014; van Buuren, Auersperg, Gajdon, Tebbich, \& von Bayern, 2018; Vanhooland, Bugnyar, \& Massen, 2020). 
Additionally, some researchers have heavily criticized the mark test in general for being ethologically invalid and methodologically flawed (Anderson \& Gallup, 2015; De Veer \& Van Den Bos, 1999; Heyes, 1994, 1995, 1996). Gallup, among others, claimed that the self-directed behaviours in front of the mirror were a direct demonstration of self-awareness, therefore interpreting with great emphasis findings based on a single paradigm (Gallup, 1970; Gallup, Steven, \& Kristina, 2014; Rochat \& Zahavi, 2011). By contrast, other researchers have proposed a more conservative or lean interpretation of self-directed behaviours. According to these researchers, MSR is not more than a sensorimotor capacity that combines visual and kinaesthetic stimuli (Heyes, 1994).

Pepperberg, for example, proposed a different approach in the use of the mirror, identifying at least two important aspects: First, the need to focus on an understanding of which mirror properties nonhuman species can process, and the underlying cognitive mechanisms required, before moving towards a more complex use to test self-awareness by using the mark test; second, the importance of operating within a comparative perspective (Pepperberg, Garcia, Jackson, \& Marconi, 1995). Pepperberg's approach to the study of mirror use was based on the idea of gradually increasing the level of cognitive complexity required by Alo and Kyaaro, two Grey parrots, to process the reflection in the mirror and succeed on each task. The parrots were exposed to the mirror and allowed to explore their reflection, providing valuable information on how the visual input provided by the mirror could impact the birds' behaviour. Overall, behaviours such as pecking the mirror, vocalizations and preening were interpreted as if the birds were facing another individual because these behaviours are normally performed within a social context. Data on Alo and Kyaaro suggests that the birds treated their reflection as a conspecific; however, on a few occasions, Alo placed her foot against the mirror and her head in a way that enabled her to have a simultaneous view of the body part and the mirror image (possible self-contingent behaviour; Pepperberg et al., 1995). In subsequent tasks, both birds were challenged with mirror-mediated object discrimination. To pass this task, the subject had to connect the information between real-world objects (some familiar, but also some novel, and either rewarding or aversive, to exclude the possibility that the mirror would just trigger searching behaviour) and their reflection, without necessarily fully understanding that the reflected images were a representation of the real object or using the mirror to monitor its movements. Based on an analysis of behavioural approach or avoidance, the data suggested that the Grey parrots' decision was based on information provided by the mirror, regardless of whether they were familiar with the object or not. When the mirror was replaced by an empty frame, the parrots behaved differently; indeed, they would pass through or detour the frame to access the positive stimulus, showing some understanding of the difference between a reflection and a direct view of the objects (Pepperberg et al., 1995). In moving towards more complex mirror use, Pepperberg also designed a mirror-mediated spatial locating task in which, to succeed, the subject had to understand the correspondence between the location of an object in real space and information reflected in the mirror. A treat was hidden in one of three compartments inside a drawer below the counter, only visible by looking at the mirror. Different controls were added by changing the original configuration, such as providing an extra compartment, changing the position of the mirror from horizontal to vertical, and using nonreflective materials. Both birds were able to find rewards in novel locations, but failed to do so in the absence of the mirror (although one subject never habituated to a mirror positioned above him; Pepperberg et al., 1995). Combining this data, it seems that Grey parrots can differentiate reflective versus nonreflective information and use a reflected representation to locate hidden objects, but they have not been examined for whether they can recognize themselves in a mirror using the mark test (or an alternative task).

Some avian species have been tested in the mirror stimulation task; few have been tested in mirror-mediated object discrimination and mirror mediated spatial location, and none in a mirror-guided reaching task (Andrew, 1966; Buniyaadi et al., 2020; Censky \& Ficken, 1982; Clary \& Kelly, 2016; Clary, Stow, Vernouillet, \& Kelly, 2020; Dally, Emery, \& Clayton, 2010; Delsaut \& Roy, 1980; Diamond \& Bond, 1989; Gallup \& Capper, 1970; Kusayama, Bischof, \& Watanabe, 2000; F. S. Medina, Taylor, Hunt, \& Gray, 2011; Pepperberg et al., 1995; Ryan, 1978; Soler et al., 2014; Uchino \& Watanabe, 2014; van Buuren et al., 2018; Vanhooland et al., 2020). Mirror-guided reaching is thought to require cognitively more advanced abilities because the subject must monitor its movement and the movement of objects reflected in the mirror-for example, to retrieve food. Since birds do not possess forearms or hands, as primates or monkeys do, tasks will need to be adapted for use with beaks and/or grasping feet (Brown, McDowell, \& Robison, 1965; Dücker \& Rensch, 1977; Menzel, Savage-Rumbaugh, \& Lawson, 1985; Pepperberg et al., 1995). However, in our view, it is possible to design tasks where birds are able to monitor their movements to guide actions through use of a mirror. For example, whether birds can use the reflection in a mirror to solve a patterned string-pulling task (Pepperberg et al., 1995) or to adjust their naturally occurring behaviour could be among the concepts examined.

An example of such investigation is the study of the effect of the mirror on the cache-protection strategies employed by some corvids species to save their food from a potential pilferer. Several studies have shown that birds recache at a higher rate when observed, compared with when they cache in private, because the risk of being pilfered when observed is higher. For example, Dally et al. (2010) showed, in scrub jays, 
that the presence of the mirror during the caching triggered recaching behaviour similar to when the birds were caching in private, and differently from when they were instead observed by another individual. The conclusion suggests that at least the jays responded differently when they were observed by a live conspecific and when they were tested using their own reflection (Dally et al., 2010). This initial study opened up the possibility that scrub jays recognized the reflected image as being themselves. Although this is a very intriguing idea, the authors stressed that it was not necessary to invoke a self-concept to explain these findings, especially when alternative explanations are possible. They suggested that the birds could have habituated to the mirror or they might have not considered the reflected image as a potential pilferer because they were a strangely-behaving stimulus. Based on this preliminary study, Clary and Kelly (2016) introduced the blurry mirror condition in addition to the three conditions used in Dally et al. (2010), and also tested the birds using the mark test. Clark's nutcrackers reduced the caching with a regular mirror (a response adopted to prevent theft from a conspecific), but not when tested with the blurry surface. Furthermore, a subgroup of birds, when tested in the formal mark test, exhibited selfdirected behaviour and attempted to remove the mark more often in the blurry compared with the regular mirror. The argument proposed by the authors is in line with the idea that birds passed the mark test because the visual information provided by the blurry mirror reduces the interference between attending to their own identity and the ability to pay attention to the contingency of their own movement (Clary \& Kelly, 2016). This preliminary result was only in part replicated in a subsequent study in California scrub jays (Clary et al., 2020). The California scrub jays increased cache protection during the blurry observed condition (not used in the previous study with the Clark's nutcrackers), and this could indicate, as suggested by the authors, that the response was not a consequence of some property of the blurry acrylic barrier, but rather that the blurry reflected image was enough to be considered as a conspecific and therefore a potential pilferer. Although this is a very intriguing suggestion, it would be important to further investigate this aspect by controlling for other confounding factors, such as auditory cues (Shaw \& Clayton, 2013, 2014). It would also be advisable to assess what the birds actually process of the visual information from these two mediums (blurry vs. mirror) based on their visual abilities before moving towards a more sophisticated use of variations of the mirror for self-recognition.

\section{Pepperberg (1995) had suggested that}

mirror use thus examines not only self-recognition but also how animals respond to reflections and process information about spatially displaced objects and actions. Specifically, because various mirror tasks require different levels of information processing, we suggest that mirror studies can provide a hierarchical scale for assessing and comparing perceptual and cognitive abilities of diverse species. (p. 2)

In order to be able to compare species on mirror use, it is thus necessary to carefully design a series of mirror tasks. The size and the position (vertical/horizontal) of the mirror, for example, can affect the propensity of the animals to explore or avoid the reflective surface. In tasks where it is required to perform some action, like mirror-guided tasks, it is important to consider the anatomical constraints of the species under examination. Rather than examining her Grey parrots' level of self-awareness, including Alex's, with the mark test, Pepperberg preferred to examine their perceptual awareness indirectly through their other cognitive abilities (such as Alex's ability to respond to

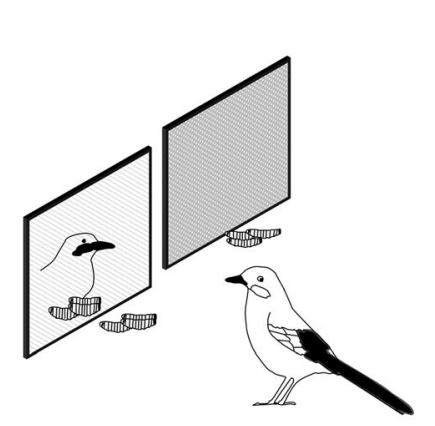

Fig. 1 The proposed approach to the study of consciousness. In order to make significant advances in the understanding of this phenomenon, it is crucial to design a series of tasks, from simpler mirror responsiveness to reflective cognition, that focus on self-awareness. In the left panel is a simple mirror preference test, in which the subject can choose between staying and eating in front of the mirror or in front a nonreflective surface. The time the bird spends and eats on each side establishes whether the subject sees the reflection as (a) a conspecific (a potential threat), (b) their own reflection or (c) an unusual stimulus. In the middle panel, the jay is

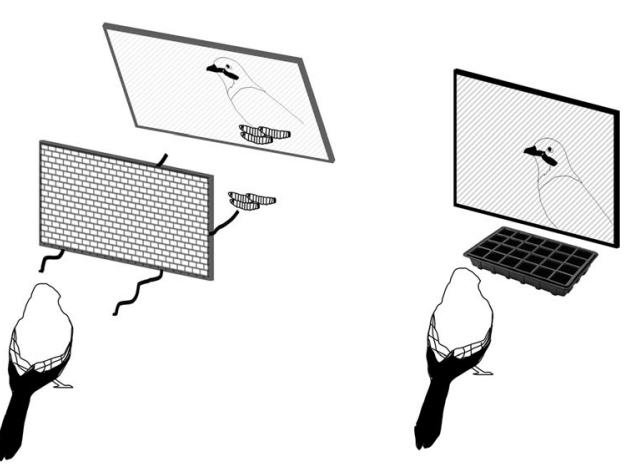

required to understand the correspondence between the real-life object, as reflected in the mirror, and its location in real space by using the wellknown string-pulling task to obtain the food from the correct side, using only the suspended mirror to see which string is baited behind the opaque barrier. In the right panel, the jay is given the opportunity to cache food in front of the mirror in order to test whether the mere presence of a reflected moving image would trigger recaching behaviour, and if so, at a similar rate to that in the observed condition when another bird is watching as opposed to the private condition where no other bird is present 
complex questions requiring the identification of a few objects out of a mixed set that fulfilled two different categorical criteria) and believed a focus on pursuing "consciousness" experimentally might not be productive. Instead, consciousness must be considered like any other psychological phenomenon that is present across taxa, to varying degrees, as a result of convergent evolution, and for which individual species might be compared according to a scale, or different degrees of awareness (Emery \& Clayton, 2004b; Osvath, Kabadayi \& Jacobs, 2014; Pepperberg \& Lynn, 2000).

\section{Conclusion and further directions}

Despite the fact that the presence of complex cognitive and metacognitive abilities posits birds as likely candidates for the demonstration of self-awareness, research on this topic has mainly been conducted through application of the mark test. Avian subjects have generally performed poorly on this task: It is indeed possible that the avian species tested simply do not recognize their own reflected image. However, the few experiments that have investigated mirror use in parrots and corvids without making use of the mark test have demonstrated their ability to use mirrors, and their reflected information, in complex ways. It is either likely, instead, that the mark test is not methodologically well suited to use with avian subjects due to some morphological or behavioural peculiarity (e.g., absence of arms), or that the mark test alone is insufficient for detecting, with enough precision, the actual presence of self-awareness in birds. Like other complex cognitive abilities, self-awareness is a multidimensional, rich phenomenon that is very unlikely to be captured by the use of any one test only (like the MSR mark test). We suggest that a methodological approach based on multiple tasks that focus on the same question and triangulate different parameters is a successful strategy to tackle this complex phenomenon in avian species, as well as across taxa (de Waal, 2019; Heyes, 1994; Perry \& Baciadonna, 2017). In Fig. 1, for example, we describe multiple tasks that involve the use of the mirror, ranging from simpler mirror responsiveness and progressing towards using the mirror to solve problems or to monitor one's own behaviours in space. Furthermore, we argue that the study of self-awareness should increasingly begin to rely on paradigms used successfully to prove the existence of other complex cognitive skills, and also on promising tests of metacognitive abilities, which have been less explored in avian cognition to date (Smith, 2009; Smith et al., 2014; Terrace \& Son, 2009). The knowledge from these paradigms should be further integrated with neurobiological studies of the neuronal aspects involved in self-awareness, based on brain similarities with mammalian species, including humans (Clayton \& Emery, 2015).

The understanding of avian brains as simple, primitive, and incapable of complex cognition seems far removed from reality today, but it was only a few decades ago that existing neurobiological frameworks and experimental data could only insufficiently detect and account for the cognitive complexity later demonstrated in avian species such as corvids and parrots. Just as arriving to this modern understanding required novel shifts in the way avian cognition and neurobiological studies were carried out and interpreted, the study of selfawareness and consciousness, especially as it relates to mirror self-recognition studies, could be better advanced by a new perspective, and a less reductive analytical lens. The careful, ecologically, and evolutionarily valid design of a series of tasks intended to examine self-awareness, either with the use of a series of mirror tasks requiring increasing cognitive processing power at each stage, or by approaching self-awareness through other abilities present in the cognitive tool kits and metacognitive abilities of corvids, parrots, and apes, will better allow for the actual extent of self-awareness in each examined species to come to light, and put future studies of selfawareness in a better position to be of comparative value across different taxa.

Acknowledgements This research was funded by the Templeton World Charity Foundation (TWCF0317), awarded to Nathan J. Emery and Nicola S. Clayton (funding L.B., N.S.C., and N.J.E.), as well as a Herchel Smith Postgraduate Fellowship (Harvard University), awarded to Francesca M. Cornero.

\section{References}

Amodio, P., Jelbert, S. A., \& Clayton, N. S. (2018). The interplay between psychological predispositions and skill learning in the evolution of tool use. Current Opinion in Behavioral Sciences, 20, 130137.

Amodio, P., Boeckle, M., Jelbert, S. A., Ostoijc, L., \& Clayton, N. S. (2019a). How flexible is tool use in Eurasian jays (Garrulus glandarius)? BioRxiv Preprint doi:https://doi.org/10.1101/803700

Amodio, P., Boeckle, M., Schnell, A. K., Ostojíc, L., Fiorito, G., \& Clayton, N. S. (2019b). Grow smart and die young: Why did cephalopods evolve intelligence? Trends in Ecology and Evolution, 34, 45-56.

Anderson, J. R., \& Gallup, G. G. (2015). Mirror self-recognition: A review and critique of attempts to promote and engineer selfrecognition in primates. Primates, 56, 317-326.

Andrew, E. (1966). Slate-colored junco response to mirror. BirdBanding, 37, 206.

Auersperg, A. M. I., \& Von Bayern, A. M. P. (2019). Who's a clever bird - now? A brief history of parrot cognition. Behaviour, 156, 391-407.

Auersperg, A. M. I., Gajdon, G. K., \& Huber, L. (2010). Kea, Nestor notabilis, produce dynamic relationships between objects in a second-order tool use task. Animal Behaviour, 80, 783-789.

Auersperg, A. M. I., Szabo, B., Von Bayern, A. M. P., \& Kacelnik, A. (2012). Spontaneous innovation in tool manufacture and use in a Goffin's cockatoo. Current Biology, 22, R903-R904.

Auersperg, A. M. I., Borasinski, S., Laumer, I., \& Kacelnik, A. (2016). Goffin's cockatoos make the same tool type from different materials. Biology Letters, 12, doi:https://doi.org/10.1098/rsbl.20160689

Bird, C. D., \& Emery, N. J. (2009a). Insightful problem solving and creative tool modification by captive nontool-using rooks. 
Proceedings of the National Academy of Sciences of the United States of America, 106, 10370-10375.

Bird, C. D., \& Emery, N. J. (2009b). Rooks use stones to raise the water level to reach a floating worm. Current Biology, 19, 1410-1414.

Bond, A. B., \& Diamond, J. (2019). Thinking like a parrot : Perspectives from the wild. Chicago, IL: University of Chicago Press.

Boswall, J. (1977). Further notes on tool-using by birds and related behaviour. Avicultural Magazine, 84, 162-166.

Brown, L. W., McDowell, A. A., \& Robison, E. M. (1965). Discrimination learning of mirrored cue by rhesus monkeys. Journal of Genetic Psychology, 106, 123-128.

Bugnyar, T., Reber, S. A., \& Buckner, C. (2016). Ravens attribute visual access to unseen competitors. Nature Communications, 7(10506). doi:https://doi.org/10.1038/ncomms10506

Buniyaadi, A., Taufique, S. K. T., \& Kumar, V. (2020). Self-recognition in corvids: Evidence from the mirror-mark test in Indian house crows (Corvus splendens). Journal of Ornithology, 161, 341-350.

Call, J., \& Carpenter, M. (2001). Do apes and children know what they have seen? Animal Cognition, 4, 207-220.

Carruthers, P. (2014). Two concepts of metacognition. Journal of Comparative Psychology, 128, 138-139.

Censky, E. J., \& Ficken, M. S. (1982). Responses of black-capped chickadees to mirrors. Wilson Bulletin, 94, 592-594.

Chakraborty, M., Walløe, S., Nedergaard, S., Fridel, E. E., Dabelsteen, T., Pakkenberg, B., ... Jarvis, E. D. (2015). Core and shell song systems unique to the parrot brain. PLOS ONE, 10, e0118496.

Cheke, L. G., \& Clayton, N. S. (2012). Eurasian jays (Garrulus glandarius) overcome their current desires to anticipate two distinct future needs and plan for them appropriately. Biology Letters, 8, 171-175.

Cheke, L. G., Bird, C. D., \& Clayton, N. S. (2011). Tool-use and instrumental learning in the Eurasian jay (Garrulus glandarius). Animal Cognition, 14, 441-455.

Clary, D., \& Kelly, D. M. (2016). Graded mirror self-recognition by Clark's nutcrackers. Scientific Reports, 6, 36459.

Clary, D., Stow, M. K., Vernouillet, A., \& Kelly, D. M. (2020). Mirrormediated responses of California scrub jays (Aphelocoma californica) during a caching task and the mark test. Ethology, 126, 140-152.

Clayton, N. S., \& Dickinson, A. (1998). Episodic-like memory during cache recovery by scrub jays. Nature, 395, 272-274.

Clayton, N. S., \& Dickinson, A. (1999). Scrub jays (Aphelocoma coerulescens) remember the relative time of caching as well as the location and content of their caches. Journal of Comparative Psychology, 113, 403-416.

Clayton, N. S., \& Emery, N. J. (2015). Avian models for human cognitive neuroscience: A proposal. Neuron, 86, 1330-1342.

Clayton, N. S., Yu, K. S., \& Dickinson, A. (2001). Scrub jays (Aphelocoma coerulescens) form integrated memories of the multiple features of caching episodes. Journal of Experimental Psychology, 27, 17-29.

Clayton, N. S., Bussey, T. J., \& Dickinson, A. (2003a). Can animals recall the past and plan for the future? Nature Reviews Neuroscience, 4 , 685-691.

Clayton, N. S., Yu, K. S., \& Dickinson, A. (2003b). Interacting cache memories: evidence for flexible memory use by Western scrub jays (Aphelocoma Californica). Journal of Experimental Psychology, 29, 14-22.

Clayton, N. S., Dally, J. M., \& Emery, N. J. (2007). Social cognition by food-caching corvids: The western scrub jay as a natural psychologist. Philosophical Transactions of the Royal Society B, 362, 507522.

Clements, K. A., Gray, S. L., Gross, B., \& Pepperberg, I. M. (2018). Initial evidence for probabilistic reasoning in a Grey parrot (Psittacus erithacus). Journal of Comparative Psychology, 132, 166-177.
Correia, S. P. C., Dickinson, A., \& Clayton, N. S. S. (2007). Western scrub jays anticipate future needs independently of their current motivational state. Current Biology, 17, 856-861.

Dally, J. M., Emery, N. J., \& Clayton, N. S. (2004). Cache protection strategies by western scrub jays (Aphelocoma californica): Hiding food in the shade. Proceedings of the Royal Society B, 271, S387S390.

Dally, J. M., Emery, N. J., \& Clayton, N. S. (2005). Cache protection strategies by western scrub jays, Aphelocoma californica: Implications for social cognition. Animal Behaviour, 70, 12511263.

Dally, J. M., Clayton, N. S., \& Emery, N. J. (2006a). The behaviour and evolution of cache protection and pilferage. Animal Behaviour, 72, $13-23$.

Dally, J. M., Emery, N. J., \& Clayton, N. S. (2006b). Food-caching western scrub jays keep track of who was watching when. Science, 312, 1662-1665.

Dally, J. M., Emery, N. J., \& Clayton, N. S. (2010). Avian theory of mind and counter espionage by food-caching western scrub jays (Aphelocoma californica). European Journal of Developmental Psychology, 7, 17-37.

Davidson, G., Miller, R., Loissel, E., Cheke, L. G., \& Clayton, N. S. (2017). The development of support intuitions and object causality in juvenile Eurasian jays (Garrulus glandarius). Scientific Reports, 7, 40062 .

De Veer, M. W., \& Van Den Bos, R. (1999). A critical review of methodology and interpretation of mirror self-recognition research in nonhuman primates. Animal Behaviour, 58, 459-468.

de Waal, F. B. M. (2019). Fish, mirrors, and a gradualist perspective on self-awareness. PLOS Biology, 17, e3000112.

Delsaut, M., \& Roy, J. C. (1980). Auditory and visual stimuli as reinforcers among lovebirds (Agapornis roseicollis). Behavioral and Neural Biology, 28, 319-334.

Diamond, J., \& Bond, A. B. (1989). Note on the lasting responsiveness of a kea (Nestor notabilis) toward its mirror image. Avicultural Magazine, 95, 92-94.

Dickinson, A., \& Balleine, B. (1995). Motivational control of instrumental action. Current Directions in Psychological Science, 4, 162-167.

Dücker, G., \& Rensch, B. (1977). The solution of patterned string problems. Behaviour, 62, 164-173.

Edinger, L. (1899). The anatomy of the central nervous system of man and of vertebrates in general (W. S. Hall, P. L. Holland, \& E. P. Cartlon, Trans.). Philadelphia, PA: F. A. Davis.

Emery, N. J. (2004). Are corvids 'feathered apes'? Cognitive evolution in crows, rooks and jackdaws. In S. Watanabe (Ed.), Comparative analysis of minds (pp. 181-213). Tokyo, Japan: Keio University Press.

Emery, N. J. (2006). Cognitive ornithology: The evolution of avian intelligence. Philosophical Transactions of the Royal Society B, 361, 23 43.

Emery, N. J. (2016). Bird brain: An exploration of avian intelligence. Princeton, NJ: Princeton University Press.

Emery, N. J., \& Clayton, N. S. (2001). Effects of experience and social context on prospective caching strategies by scrub jays. Nature, 414 , 443-446.

Emery, N. J., \& Clayton, N. S. (2004a). Comparing the complex cognition of birds and primates. In L. J. Rogers \& G. Kaplan (Eds.), Comparative vertebrate cognition (pp. 3-55). Boston, MA: Springer.

Emery, N. J, \& Clayton, N. S. (2004b). The mentality of crows: Convergent evolution of intelligence in corvids and apes. Science, 306, 1903-1907.

Emery, N. J, \& Clayton, N. S. (2008). How to build a scrub jay that reads minds. In S. Itakura \& K. Fujita (Eds.), Origins of the social mind: Evolutionary and developmental views (pp. 65-97). New York, NY: Springer. 
Emery, N. J., \& Clayton, N. S. (2009a). Comparative social cognition. Annual Review of Psychology, 60, 87-113.

Emery, N. J., \& Clayton, N. S. (2009b). Tool use and physical cognition in birds and mammals. Current Opinion in Neurobiology, 19, 2733.

Emery, N. J, Seed, A. M., von Bayern, A. M. P., \& Clayton, N. S. (2007). Cognitive adaptations of social bonding in birds. Philosophical Transactions of the Royal Society B, 362, 489-505.

Fernandez-Duque, D., Baird, J. A., \& Posner, M. I. (2000). Executive attention and metacognitive regulation. Consciousness and Cognition, 9, 288-307.

Fox, K. C. R., Muthukrishna, M., \& Shultz, S. (2017). The social and cultural roots of whale and dolphin brains. Nature Ecology and Evolution, 1, 1699-1705.

Gallup, G G. (1970). Chimpanzees: self-recognition. Science, 167, 8687.

Gallup, G. G, \& Anderson, J. R. (2018). The "olfactory mirror” and other recent attempts to demonstrate self-recognition in non-primate species. Behavioural Processes, 148, 16-19.

Gallup, G. G., \& Capper, S. A. (1970). Preference for mirror-image stimulation in finches (Passer domesticus domesticus) and parakeets (Melopsittacus undulatus). Animal Behaviour, 18, 621-624.

Gallup, G. G., Steven, P., \& Kristina, S. (2014). The nature of visual selfrecognition. Trends in Cognitive Sciences, 18(2), 57-58. doi:https:// doi.org/10.1016/j.tics.2013.10.012

Gardner, R. A., \& Gardner, B. T. (1969). Teaching sign language to a chimpanzee. Science, 187, 664-672.

Griffiths, D., Dickinson, A., \& Clayton, N. (1999). Episodic memory: What can animals remember about their past? Trends in Cognitive Sciences, 3, 74-80.

Grodzinski, U., \& Clayton, N. S. (2010). Problems faced by food-caching corvids and the evolution of cognitive solutions. Philosophical Transactions of the Royal Society B, 365, 977-987.

Grodzinski, U., Watanabe, A., \& Clayton, N. S. (2012). Peep to pilfer: What scrub jays like to watch when observing others. Animal Behaviour, 83, 1253-1260.

Gruber, R., Schiestl, M., Boeckle, M., Frohnwieser, A., Miller, R., Gray, R. D., ... Taylor, A. H. (2019). New Caledonian crows use mental representations to solve metatool problems. Current Biology, 29, 686-692.

Güntürkün, O. (2005). The avian 'prefrontal cortex' and cognition. Current Opinion in Neurobiology, 15, 686-693.

Güntürkün, O., \& Bugnyar, T. (2016). Cognition without cortex. Trends in Cognitive Sciences, 20, 291-303.

Gutiérrez-Ibáñez, C., Iwaniuk, A. N., \& Wylie, D. R. (2018). Parrots have evolved a primate-like telencephalic-midbrain-cerebellar circuit. Scientific Reports, 8(1). doi:https://doi.org/10.1038/s41598-01828301-4

Hessler, N. A., \& Doupe, A. J. (1999). Social context modulates singingrelated neural activity in the songbird forebrain. Nature Neuroscience, 2, 209-211.

Heyes, C. M. (1994). Reflections on self-recognition in primates. Animal Behaviour, 47, 909-919.

Heyes, C. M. (1995). Self-recognition in primates: Further reflections create a hall of mirrors. Animal Behaviour, 50, 1533-1542.

Heyes, C. M. (1996). Self-recognition in primates: Irreverence, irrelevance and irony. Animal Behaviour, 51, 470-473.

Iwaniuk, A. N., Dean, K. M., \& Nelson, J. E. (2005). Interspecific allometry of the brain and brain regions in parrots (Psittaciformes): Comparisons with other birds and primates. Brain, Behavior and Evolution, 65, 40-59.

Jacobs, I. F., von Bayern, A., \& Osvath, M. (2016). A novel tool-use mode in animals: New Caledonian crows insert tools to transport objects. Animal Cognition, 19, 1249-1252.

Jarvis, E. D., Güntürkün, O., Bruce, L., Csillag, A., Karten, H., Kuenzel, W., ... Butler, A. B. (2005). Avian brains and a new understanding of vertebrate brain evolution. Nature Reviews Neuroscience, 6, 151159.

Jarvis, E. D., Yu, J., Rivas, M. V., Horita, H., Feenders, G., Whitney, O., ... Wada, K. (2013). Global view of the functional molecular organization of the avian cerebrum: Mirror images and functional columns. Journal of Comparative Neurology, 521, 3614-3665.

Jelbert, S. A., Taylor, A. H., Cheke, L. G., Clayton, N. S., \& Gray, R. D. (2014). Using the Aesop's fable paradigm to investigate causal understanding of water displacement by New Caledonian crows. PLOS ONE, 9, e92895.

Jelbert, S. A., Taylor, A. H., \& Gray, R. D. (2015). Investigating animal cognition with the Aesop's Fable paradigm: Current understanding and future directions. Communicative \& Integrative Biology, 8(4). doi:https://doi.org/10.1080/19420889.2015.1035846

Kabadayi, C., \& Osvath, M. (2017). Ravens parallel great apes in flexible planning for tool-use and bartering. Science, 357, 202-204.

Kabadayi, C., Bobrowicz, K., \& Osvath, M. (2018). The detour paradigm in animal cognition. Animal Cognition, 21, 21-35.

Keefner, A. (2016). Corvids infer the mental states of conspecifics. Biology \& Philosophy, 31, 267-281.

Kusayama, T., Bischof, H.-J., \& Watanabe, S. (2000). Responses to mirror-image stimulation in jungle crows (Corvus macrorhynchos). Animal Cognition, 3, 61-64.

Lambert, M. L., Jacobs, I., \& Osvath, M. (2018). Birds of a feather ? Parrot and corvid cognition compared. Behaviour, 156, 505-594.

Laumer, I. B., Bugnyar, T., Reber, S. A., \& Auersperg, A. M. I. (2017). Can hook-bending be let off the hook? Bending/unbending of pliant tools by cockatoos. Proceedings of the Royal Society B, 284(1862). doi:https://doi.org/10.1098/rspb.2017.1026

Lefebvre, L., Nicolakakis, N., \& Boire, D. (2002). Tools and brains in birds. Behaviour, 139, 939-973.

Legg, E. W., \& Clayton, N. S. (2014). Eurasian jays (Garrulus glandarius) conceal caches from onlookers. Animal Cognition, 17 , 1223-1226.

Legg, E. W., Ostojić, L., \& Clayton, N. S. (2016). Caching at a distance: a cache protection strategy in Eurasian jays. Animal Cognition, 19, $753-758$.

Lorenz, K. (1952). King Solomon's Ring: New light on animal ways. New York, NY: Crowell.

Marino, L. (2002). Convergence of complex cognitive abilities in cetaceans and primates. Brain, Behavior and Evolution, 59, 21-32.

Marino, L., Connor, R. C., Fordyce, R. E., Herman, L. M., Hof, P. R., Lefebvre, L., ... Whitehead, H. (2007). Cetaceans have complex brains for complex cognition. PLOS Biology, 5, e139.

Marler, P. (1970). A comparative approach to vocal learning: Song development in white-crowned sparrows. Journal of Comparative and Physiological Psychology, 71, 1-25.

Medina, F. S., Taylor, A. H., Hunt, G. R., \& Gray, R. D. (2011). New Caledonian crows' responses to mirrors. Animal Behaviour, 82, 981-993.

Medina, L., \& Reiner, A. (2000). Do birds possess homologues of mammalian primary visual, somatosensory and motor cortices? Trends in Neurosciences, 23, 1-12.

Menzel, E. W., Savage-Rumbaugh, E. S., \& Lawson, J. (1985). Chimpanzee (Pan troglodytes) spatial problem solving with the use of mirrors and televised equivalents of mirrors. Journal of Comparative Psychology, 99, 211-217.

Metcalfe, J. (2009). Metacognitive judgments and control of study. Current Directions in Psychological Science, 18, 159-163.

Mikolasch, S., Kotrschal, K., \& Schloegl, C. (2011). African Grey parrots (Psittacus erithacus) use inference by exclusion to find hidden food. Biology Letters, 7, 875-877.

Miller, R., Logan, C. J., Lister, K., \& Clayton, N. S. (2016). Eurasian jays do not copy the choices of conspecifics, but they do show evidence of stimulus enhancement. PeerJ, 2016, e2746. 
Mowrer, O. H. (1950). Learning theory and personality dynamics: Selected papers. New York, NY: Ronald Press.

Nottebohm, F. (1970). Ontogeny of bird song. Science, 167, 950-956.

Nottebohm, F. (1980). Brain pathways for vocal learning in birds: A review of the first 10 years. Progress in Psychobiology and Physiological Psychology, 9, 85-124.

Olkowicz, S., Kocourek, M., Luèan, R. K., Porteš, M., Fitch, W. T., Herculano-Houzel, S., \& Nemec, P. (2016). Birds have primatelike numbers of neurons in the forebrain. Proceedings of the National Academy of Sciences of the United States of America, 113, 7255-7260.

Ostojić, L., Shaw, R. C., Cheke, L. G., \& Clayton, N. S. (2013). Evidence suggesting that desire-state attribution may govern food sharing in Eurasian jays. Proceedings of the National Academy of Sciences of the United States of America, 110, 4123-4128.

Ostojić, L., Legg, E. W., Shaw, R. C., Cheke, L. G., Mendl, M., \& Clayton, N. S. (2014). Can male Eurasian jays disengage from their own current desire to feed the female what she wants. Biology Letters, 10, 20140042.

Ostojić, L., Cheke, L. G., Shaw, R. C., Legg, E. W., \& Clayton, N. S. (2016). Desire-state attribution: Benefits of a novel paradigm using the food-sharing behavior of eurasian jays (Garrulus glandarius). Communicative and Integrative Biology, 9, 1-3.

Osuna-Mascaró, A. J., \& Auersperg, A. M. I. (2018). Animal behavior and cognition on the brink of tool use? Could object combinations during foraging in a feral Goffin's cockatoo (Cacatua goffiniana) result in tool innovations? Animal Behavior and Cognition, 5, 229234.

Osvath, M., Kabadayi, C., \& Jacobs, I. (2014). Independent evolution of similar complex cognitive skills: The importance of embodied degrees of freedom. Animal Behavior and Cognition, 1, 249-264.

Pepperberg, I. M. (1987a). Acquisition of the same/different concept by an African Grey parrot (Psittacus erithacus): Learning with respect to categories of color, shape, and material. Animal Learning \& Behavior, 15, 423-432.

Pepperberg, I. M. (1987b). Evidence for conceptual quantitative abilities in the African Grey parrot: labeling of cardinal sets. Ethology, 75, $37-61$.

Pepperberg, I. M. (1988). Comprehension of "absence" by an African Grey parrot: Learning with respect to questions of same/different. Journal of the Experimental Analysis of Behavior, 50, 553-564.

Pepperberg, I. M. (1992a). Proficient performance of a conjunctive, recursive task by an African gray parrot (Psittacus erithacus). Journal of Comparative Psychology, 106, 295-305.

Pepperberg, I. M. (1992b). A review of the effects of social interaction on vocal learning in African Grey parrots (Psittacus erithacus). Netherlands Journal of Zoology, 43, 104-124.

Pepperberg, I. M. (1992c). Social interaction as a condition for learning in avian species: A synthesis of the disciplines of ethology and psychology. In D. Hank \& B. Dianne (Eds.), The inevitable bond (pp. 178-204). Cambridge, England: Cambridge University Press.

Pepperberg, I. M. (1994a). Numerical competence in an African Grey parrot (Psittacus erithacus). Journal of Comparative Psychology, $108,36-44$

Pepperberg, I. M. (1994b). Vocal learning in Grey parrots (Psittacus erithacus): Effects of social interaction, reference, and context. The Auk, 111, 300-313.

Pepperberg, I. M. (1999). The Alex studies : Cognitive and communicative abilities of grey parrots. Cambridge, MA: Harvard University Press.

Pepperberg, I. M. (2000). Adaptive behavior and learning: How cognitive processing and social interaction might affect allospecific vocal learning in Grey parrots (Psittacus erithacus). In H. Ritter, H. Cruse, \& J. Dean (Eds.), Prerational intelligence (pp. 1098-1117). Dordrecht, Netherlands: Springer. doi:https://doi.org/10.1007/97894-010-0870-9 69
Pepperberg, I. M. (2002a). Cognitive and communicative abilities of grey parrots. Current Directions in Psychological Science, 11, 83-87.

Pepperberg, I. M. (2002b). In search of King Solomon's Ring: Cognitive and communicative studies of grey parrots (Psittacus erithacus). Brain, Behavior and Evolution, 59, 54-67.

Pepperberg, I. M. (2006a). Grey Parrot (Psittacus erithacus) numerical abilities: addition and further experiment on a zero-like concept. Journal of Comparative Psychology, 120, 1:11.

Pepperberg, I. M. (2006b). Ordinality and inferential abilities of a grey parrots (Psittacus erithacus). Journal of Comparative Psychology, 120, 205:216.

Pepperberg, I. M., \& Brezinsky, M. V. (1991). Acquisition of a relative class concept by an African Grey parrot (Psittacus erithacus): Discriminations based on relative size. Journal of Comparative Psychology, 105, 286-294.

Pepperberg, I. M., \& Gordon, J. D. (2005). Number comprehension by a Grey parrot (Psittacus erithacus), including a zero-like concept. Journal of Comparative Psychology, 119, 197-209.

Pepperberg, I. M., \& Lynn, S. K. (2000). Possible levels of animal consciousness with reference to Grey parrots (Psittacus erithacus). American Zoologist, 40, 893-901.

Pepperberg, I. M., \& Wilkes, S. R. (2004). Lack of referential vocal learning from LCD video by Grey parrots (Psittacus erithacus). Interaction Studies, 5, 75-97.

Pepperberg, I. M., \& Carey, S. (2012). Grey parrot number acquisition: the inference of cardinal value from ordinal position on the numeral list. Cognition 125, 219-232.

Pepperberg, I. M., Garcia, S. E., Jackson, E. C., \& Marconi, S. (1995). Mirror use by African Grey parrots (Psittacus erithacus). Journal of Comparative Psychology, 109, 182-195.

Pepperberg, I. M., Gardiner, L. I., \& Luttrell, L. J. (1999). Limited contextual vocal learning in the Grey parrot (Psittacus erithacus): The effect of interactive co-viewers on videotaped instruction. Journal of Comparative Psychology, 113, 158-172.

Pepperberg, I. M., Koepke, A., Livingston, P., Girard, M., \& Hartsfield, L. A. (2013). Reasoning by inference: Further studies on exclusion in Grey parrots (Psittacus erithacus). Journal of Comparative Psychology, 127, 272-281.

Pepperberg, I. M., Gray, S. L., Mody, S., Cornero, F. M., \& Carey, S. (2019). Logical reasoning by a Grey parrot? A case study of the disjunctive syllogism. Behaviour, 156, 409-445.

Perry, C. J., \& Baciadonna, L. (2017). Studying emotion in invertebrates: What has been done, what can be measured and what they can provide. Journal of Experimental Biology, 220, 3856-3868.

Plotnik, J. M., \& Clayton, N. S. (2015). Convergent cognitive evolution across animal taxa: Comparisons of chimpanzees, corvids and elephants. In E. Margolis \& S. Laurence (Eds.), The conceptual mind: New direction in the study of concepts (pp. 29-55). Cambridge, MA: MIT Press.

Premack, D. (1971). On the assessment of language competence in the chimpanzee. In A. Schrier \& F. Stollnitz (Eds.), Behavior of nonhuman primates (pp. 186-228). Amsterdam, Netherlands: Elsevier. doi:https://doi.org/10.1016/B978-0-12-629104-9.50011-X

Prior, H., Schwarz, A., \& Güntürkün, O. (2008). Mirror-induced behavior in the magpie (Pica pica): Evidence of self-recognition. PLOS Biology, 6, e202.

Raby, C. R., Alexis, D. M., Dickinson, A., \& Clayton, N. S. (2007). Planning for the future by western scrub jays. Nature, 445, 919-921.

Reiner, A., Perkel, D. J., Bruce, L. L., Butler, A. N. N. B., Kuenzel, W., Medina, L., ... Durand, S. (2004). Revised nomenclature for avian telencephalon and some related brainstem nuclei. Journal of Comparative Neurology, 473, 377-414.

Rochat, P., \& Zahavi, D. (2011). The uncanny mirror: A re-framing of mirror self-experience. Consciousness and Cognition, 20, 204-213. 
Roth, G. (2015). Convergent evolution of complex brains and high intelligence. Philosophical Transactions of the Royal Society B, 370, 20150049.

Rumbaugh, D. M., Gill, T. V., Brown, J. V., von Glasersfeld, E. C., Pisani, P., Warner, H., \& Bell, C. L. (1973). A computercontrolled language training system for investigating the language skills of young apes. Behavior Research Methods \& Instrumentation, 5, 385-392.

Rutz, C., Klump, B. C., Komarczyk, L., Leighton, R., Kramer, J., Wischnewski, S., ... Masuda, B. M. (2016a). Discovery of species-wide tool use in the Hawaiian crow. Nature, 537, 403-407.

Rutz, C., Sugasawa, S., van der Wal, J. E. M., Klump, B. C., \& St Clair, J. J. H. (2016b). Tool bending in new caledonian crows. Royal Society Open Science, 3, 160439.

Ryan, M. J. (1978). Mirror image versus conspecific stimulation in adult male zebra finches. The Wilson Bulletin, 90, 295-297.

Sanz, C. M., Call, J., \& Boesch, C. (2013). Tool use in animals: Cognition and ecology. Cambridge, England: Cambridge University Press.

Seed, A., \& Byrne, R. (2010). Animal tool-use. Current Biology, 20, R1032-R1039.

Seed, A., Emery, N., \& Clayton, N. (2009). Intelligence in corvids and apes: A case of convergent evolution? Ethology, 115, 401-420.

Shaw, R. C., \& Clayton, N. S. (2013). Careful cachers and prying pilferers: Eurasian jays (Garrulus glandarius) limit auditory information available to competitors. Proceedings of the Royal Society B, 280. doi:https://doi.org/10.1098/rspb.2012.2238

Shaw, R. C., \& Clayton, N. S. (2014). Pilfering Eurasian jays use visual and acoustic information to locate caches. Animal Cognition, 17, $1281-1288$

Shimizu, T., \& Watanabe, S. (2012). The avian visual system. In O. Lazareva, T. Shimizu, \& E. Wasserman (Eds.), How animals see the world: Comparative behaviour, biology and evolution (pp. 473482). Oxford, England: Oxford University Press.

Shimizu, T., Patton, T. B., \& Husband, S. A. (2010). Avian visual behavior and the organization of the telencephalon. Brain, Behavior and Evolution, 75, 204-217.

Shumaker, R. W., Walkup, K. R., \& Beck, B. B. (2011). Animal tool behavior: The use and manufacture of tools by animals. Baltimore, MD: Johns Hopkins University Press.

Smith, J. D. (2009). The study of animal metacognition. Trends in Cognitive Science, 13, 389-396.

Smith, J. D., Couchman, J. J., \& Beran, M. J. (2014). Animal metacognition: A tale of two comparative psychologies. Journal of Comparative Psychology, 128, 115-131.

Soler, M., Pérez-Contreras, T., \& Peralta-Sánchez, J. M. (2014). Mirrormark tests performed on jackdaws reveal potential methodological problems in the use of stickers in avian mark-test studies. PLOS ONE, 9, 86193

Suddendorf, T., \& Corballis, M. C. (1997). Mental time travel and the evolution of the human mind. Genetic, Social, and General Psychology Monographs, 123, 133-167.

Suddendorf, T., Addis, D. R., \& Corballis, M. C. (2009). Mental time travel and the shaping of the human mind. Philosophical Transactions of the Royal Society B, 364, 1317-1324.

Taylor, A. H., Hunt, G. R., Holzhaider, J. C., \& Gray, R. D. (2007). Spontaneous metatool use by New Caledonian crows. Current
Biology, 17, 1504-1507. doi:https://doi.org/10.1016/j.cub.2007.07. 057

Tebbich, S., Taborsky, M., \& Winkler, H. (1996). Social manipulation causes cooperation in keas. Animal Behaviour, 52, 1-10.

Terrace, H. S., \& Son, L. K. (2009). Comparative metacognition. Current Opinion in Neurobiology, 19, 67-74.

Thorpe, W. H. (1964). Learning and instinct in animals. London, England: Methuen \& Co. Ltd.

Todt, D. (1975). Social learning of vocal patterns and modes of their application in Grey parrots. Zeitschrift Für Tierpsychologie, 39, 178-188.

Tomasello, M., \& Call, J. (1997). Primate cognition. New York, NY: Oxford University Press.

Tornick, J. K., Rushia, S. N., \& Gibson, B. M. (2016). Clark's nutcrackers (Nucifraga columbiana) are sensitive to distance, but not lighting when caching in the presence of a conspecific. Behavioural Processes, 123, 125-133.

Tulving, E. (2005). Episodic memory and autonoesis: Uniquely human? In H. Terrace \& J. Metcalfe (Eds.), The missing link in cognition: Origins in self-reflective consciousness (pp. 3-56). Oxford, England: Oxford University Press.

Uchino, E., \& Watanabe, S. (2014). Self-recognition in pigeons revisited. Journal of the Experimental Analysis of Behavior, 102, 327-334.

van Buuren, M., Auersperg, A., Gajdon, G., Tebbich, S., \& von Bayern, A. (2018). No evidence of mirror self-recognition in keas and Goffin's cockatoos. Behaviour, 156, 763-786.

van Horik, J., \& Emery, N. J. (2011). Evolution of cognition. Wiley Interdisciplinary Reviews: Cognitive Science, 2, 621-633.

van Horik, J. O., Clayton, N. S., \& Emery, N. J. (2012). Convergent evolution of cognition in corvids, apes and other animals. In J. Vonk \& T. Shackleford (Eds.), Oxford handbook of comparative evolutionary psychology (pp. 80-101). Oxford, England: Oxford University Press.

Vanhooland, L.-C., Bugnyar, T., \& Massen, J. J. M. (2020). Crows (Corvus corone ssp.) check contingency in a mirror yet fail the mirror-mark test. Journal of Comparative Psychology, 134, 158169.

von Bayern, A. M. P., \& Emery, N. J. (2009a). Bonding, mentalising and rationality. In S. Watanabe, A. Blaisdell, L. Huber, \& A. Young (Eds.), Rational animals, irrational human (pp. 287-303). Tokyo, Japan: Keio University Press.

von Bayern, A. M. P., \& Emery, N. J. (2009b). Jackdaws respond to human attentional states and communicative cues in different contexts. Current Biology, 19, 602-606.

Watanabe, A., Grodzinski, U., \& Clayton, N. S. (2014). Western scrub jays allocate longer observation time to more valuable information. Animal Cognition, 17, 859-867.

Weir, A. A. S., Chappell, J., \& Kacelnik, A. (2002). Shaping of hooks in New Caledonian crows. Science, 297(5583), 981. doi:https://doi. org/10.1126/science. 1073433

Wood, G. A. (1984). Tool use by the palm cockatoo Probosciger aterrimus during display. Corella, 8, 95-95.

Wynne, C. D. L., \& Udell, M. A. R. (2013). Animal cognition : Evolution, behavior and cognition. New York, NY: Palgrave Macmillan.

Publisher's note Springer Nature remains neutral with regard to jurisdictional claims in published maps and institutional affiliations. 